\title{
Spatial Distribution and Factors Associated with Khat Chewing among Adult Males 15-59 Years in Ethiopia Using a Secondary Analysis of Ethiopian Demographic and Health Survey 2016: Spatial and Multilevel Analysis
}

\author{
Zemenu Tadesse Tessema $\mathbb{D}^{1}$ and Tadele Amare Zeleke ${ }^{2}$ \\ ${ }^{1}$ Department of Epidemiology and Biostatics, Institute of Public Health College of Medicine and Health Sciences, \\ University of Gondar, Gondar, Ethiopia \\ ${ }^{2}$ Department of Psychiatry, School of Medicine, College of Medicine and Health Science, University of Gondar, Gondar, Ethiopia \\ Correspondence should be addressed to Zemenu Tadesse Tessema; zemenut1979@gmail.com
}

Received 25 January 2020; Revised 16 March 2020; Accepted 3 April 2020; Published 21 April 2020

Academic Editor: James Grutsch

Copyright ( 2020 Zemenu Tadesse Tessema and Tadele Amare Zeleke. This is an open access article distributed under the Creative Commons Attribution License, which permits unrestricted use, distribution, and reproduction in any medium, provided the original work is properly cited.

Background. Khat chewing has become prevalent in the world due to the improvement of road and air transportation. In Ethiopia, khat chewing is more prevalent and widely practiced by men. Khat has a negative effect on social, economic, and mental health. There is variation in khat cultivation, use, and factors that associated with khat chewing in the Ethiopian regions. Therefore, this study is aimed at showing spatial distribution and factors associated with khat chewing among male adults 15-59 years in Ethiopia. Methods. A total of 12,594 men were included in this study. ArcGIS version 10.7 software was used to show the spatial distribution of chewing khat among adult men in Ethiopia. The Bernoulli model was applied using Kilduff SaTScan version 9.6 software to identify significant purely spatial clusters for chewing khat in Ethiopia. A multilevel logistic regression model was fitted to identify factors associated with khat chewing. A $P$ value $<0.05$ was taken to declare statistically significant predictors. Results. The EDHS 2016 survey showed that the high proportion of chewing khat was found in Dire Dawa, Harari, Southern Oromia, Somali, and Benishangul Gumuz regions. In spatial scan statistics analysis, a total of 126 clusters (LLR $=946.60$, $P$ value $<0.001)$ were identified. Age group 30-44 years old (AOR=1.60, 95\% CI: 1.37, 1.86) and 45-59 years old $(\mathrm{AOR}=1.33,95 \% \mathrm{CI}: 1.09,1.61)$, being single $(\mathrm{AOR}=1.86,95 \% \mathrm{CI}: 1.64,2.12)$, Muslim religion followers $(\mathrm{AOR}=15.03$, 95\% CI: 11.90, 18.90), media exposed $(\mathrm{AOR}=0.77,95 \% \mathrm{CI}: 0.68,0.86)$, had work (AOR $=2.48,95 \% \mathrm{CI}: 2.08,2.95)$, alcohol drinker $(\mathrm{AOR}=3.75,95 \% \mathrm{CI}: 3.10,4.53)$, and region (Afar, Amhara, Benishangul Gumuz, Gambela, Harari, Oromia, Somali, Southern Nations, Nationalities, and People's Region (SNNPR), and Tigray) and two cities (Addis Ababa and Dire Dawa) were statistically significant factors affecting chewing khat in Ethiopia. Conclusions. In Ethiopia, the spatial distribution of khat chewing among adult men was nonrandom. A high proportion of khat chewing was observed in Dire Dawa, Harari, Southern Oromia, Somali, and Benishangul Gumuz regions. Older age group, being single marital status, alcohol drinker, media unexposed, had no work, and Muslim religion follower were factors affecting khat chewing. Policymakers should be given spatial attention in reducing the prevalence of chewing khat by teaching the health impact of khat chewing through media in the identified regions.

\section{Background}

Khat is an evergreen shrub cultivated as a bush or small tree native to Ethiopia, East Africa, and the southern Arabian
Peninsula [1]. Its young buds and tender leaves contain amphetamine-like psychoactive substances, which produce euphoria and stimulation [2]. In Yemen and the Jazan region of Saudi Arabia, the prevalence of khat chewing has been 
high. According to global synthetic drug assessment in 2014, in Yemen, the prevalence of khat chewing among people aged 16 and above was 52\% [3].

Globally, even though the exact number is not known, about 5 to 10 million people use khat in the world [4]. According to the United Nations, Office on Drugs and Crime reported that about $72 \%$ of Yemeni men and $32.6 \%$ of women used khat in 2006 [5]. In other study, chewing khat among Yemeni men and women was $90 \%$ and $60 \%$, respectively [6]. In Somalis living in London, the prevalence of khat chewing in a week was 67\% [7]. In Saudi Arabia, the prevalence of current khat use among men was 36.9\% [8].

Based on EDHS 2016, the prevalence of ever chewed khat was $12 \%$ and $27 \%$ of women and men, respectively [9]. Khat consumption increases with age and peaks at age 30-34 among both women (15\%) and men (34\%) [9].

Khat chewing had an impact on physical health (loss of teeth, gum disease, and mouth problems); constipation; stomach problems; weight loss; sleeplessness; cardiovascular problems such as heart attacks, high blood pressure, and stroke; diabetes; respiratory problems; male impotence; and bowel cancer from the chemicals sprayed on khat $[5,10-12]$. Reasons for khat use were peer pressure, academic performance, alertness, feeling excitement, and well-being $[13,14]$.

The major predisposing factors for khat chewing include a family member who had a history of chewing khat $[15,16]$, the reason for concentration and relaxation $[15,17]$, alcohol drunker [18], Muslim religion follower, age 45 to 49, and attended mass media [19-21]. In Ethiopian regions, Oromia, Southern Nations, Nationalities, and People's Region (SNNPR), Gambela, Harari, and Dire Dawa were also significant factors for khat use [20].

There is variation in khat cultivation, use, and factors that associated with khat chewing in the Ethiopian regions. Even though different studies tried to show the predisposing factors for khat chewing in Ethiopia, the spatial distribution of khat chewing was not done before. Identifying the spatial distribution and factors of khat chewing in Ethiopia can help health planners and policymakers for specific interventions to decrease khat chewing.

Therefore, this study is aimed at assessing the spatial distribution and factors associated with khat chewing among adults aging 15-59 years in Ethiopia.

\section{Methods}

2.1. Study Design, Period, and Setting. A population-based cross-sectional study was conducted from January 18 to June 27, 2016. Ethiopia is located in the horn of Africa. It has a total area of $1,100,000 \mathrm{~km}^{2}$ and lies between latitudes $3^{\circ}$ and $15^{\circ} \mathrm{N}$ and longitudes $33^{\circ}$ and $48^{\circ} \mathrm{E}$. Ethiopia has nine regions (Afar, Amhara, Benishangul Gumuz, Gambela, Harari, Oromia, Somali, Southern Nations, Nationalities, and People's Region (SNNPR), and Tigray) and two administrative cities (Addis Ababa and Dire Dawa) (Figure 1).

2.2. Source and Study Population. The source population was all men from 15 to 59 years in Ethiopia. The study population was all men aging from 15 to 59 in the selected enumeration

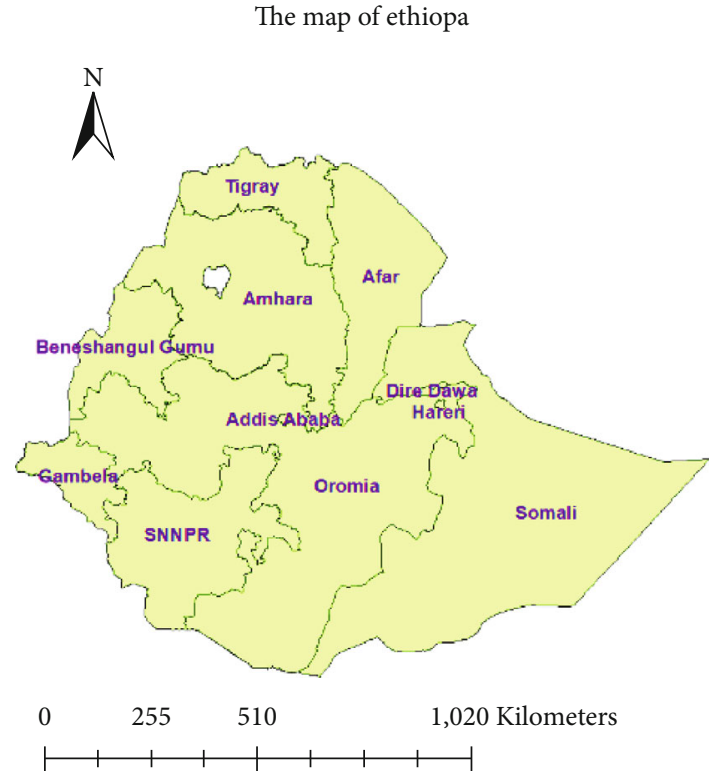

FIgURE 1: Study areas of nine regions and two city administrations in Ethiopia, EDHS 2016.

areas. All men aging 15-59 who had interviewed about ever chewed khat were included in the study. However, respondents with missing data for the outcome variable were excluded from the study.

2.3. Sample Size and Sampling Procedure. A total of 12,594 men were included in this study. Weighted values were used to restore the representatives of the sample data. Sample weights were calculated in each Men's Record (MR) EDHS datasets. The survey covered all nine regions and the two city administrations of Ethiopia. Participants were selected based on a stratified two-stage cluster sampling technique in each survey year EDHS 2016. After excluding clusters with no recorded $x$ and y coordinates, a total of 621 clusters in 2016 were encompassed in this study. The detail sampling procedure was available in each EDHS reports from measure DHS website (http://www.dhsprogram.com).

2.4. Data Collection Tools and Procedures. The data were obtained from the Ethiopian Demographic and Health Surveys (EDHS) Program by requesting for this work and accessing ht6 were encompassed http://www.dhsprogram.com website. Ethiopian Demographic and Health Survey data were collected by two-stage stratified sampling. Each region of the country was stratified into urban and rural areas.

\section{Variables}

3.1. Outcome Variables. The outcome variable is taken as binary response men who ever chewed khat in his life coded as " 1 " and men who do not chew chat in his life is coded as " 0. "

3.2. Independent Variables. From the WR EDHS dataset, all sociodemographic, socioeconomic, and lifestyle variables (individual and community level) were taken as independent in this study. Only two variables residence and region were 
collected at the community level. The individual-level variables considered the following: age group, religion, marital status, educational status, alcohol drinking, and media exposure (if men use at least one from the three taken as media exposed: reading a newspaper, reading magazines, and watching television); wealth ranking was grossly categorized into 5 major quintiles lowest (poorest), second (poorer), middle (middle), fourth (richer), and highest (richest), which we recategorized into three "poor (poorest+poor), middle, and rich (richest+rich)" for ease of analysis. The independent variables were screened based on different literatures $[16,17,19$, 20, 22-24].

3.3. Operational Definition. Ever khat chewer is defined as a respondent whoever chewed khat during his lifetime.

Alcohol drinking is defined as a respondent who drank alcohol during one month preceding the survey at least once per month.

3.3.1. Data Management. STATA version 14.1, excel, and ArcGIS 10.1 were used for statistical and spatial analysis, respectively. Sample weighting was done before further analysis.

\section{Analysis}

\subsection{Geospatial Analysis}

4.1.1. Spatial Distribution of Khat Chewing in Ethiopia. Among a total of 643 clusters, 621 were considered for the spatial analysis of khat chewing in Ethiopia (21 clusters dropped because of no coordinate data in the cluster). Each point on the map represents one enumeration area with a prevalence of khat chewing in each cluster.

4.1.2. Spatial Autocorrelation Analysis. The spatial autocorrelation (Global Moran's I) statistic measures whether the khat chewing patterns were dispersed, clustered, or randomly distributed in the study area [25]. "Moran's I" is a spatial statistics used to measure spatial autocorrelation by taking the entire dataset and produce a single output value which ranges from -1 to +1 . Moran's I values close to $-1,1$, and 0 indicate disease dispersed, disease clustered, and disease distributed randomly, respectively. A statistically significant Moran's I $(P<0.05)$ leads to rejection of the null hypothesis (khat chewing is randomly distributed) and indicates the presence of spatial autocorrelation.

4.1.3. Incremental Autocorrelation. Measuring spatial autocorrelation for a series of distances optionally creates a line graph of those distances and their corresponding $Z$ -scores.Z-scores show the intensity of spatial clustering and statistical significance. Peak $Z$-scores show distances where spatial processes promoting clustering are most pronounced. These peak distances are often proper values to use for tools with a Distance Band or Distance Radius parameter. This tool can help to select an appropriate distance threshold or radius for tools that have these parameters, such as hot spot analysis [25].
4.1.4. Hot Spot Analysis (Getis-OrdGi* Statistic). GetisOrdGi* $^{*}$ statistic was computed to measure how spatial autocorrelation varies over the study site by calculating GI $^{*}$ statistic for each area. $Z$-score is computed to find the statistical significance of clustering, and the $P$ value is computed for the significance. Statistical output with high GI* indicates "hotspot" whereas low GI* means a "cold spot."

4.1.5. Spatial Scan Statistical Analysis. A Bernoulli-based model was used in which events at particular places were analyzed if adults whether chewing chat or not coded as $1 / 0$ variable. The scan statistics developed by Kulldorff and SaTS$\mathrm{can}^{\mathrm{TM}}$ software version 9.6 were used to identify the presence of purely spatial home deliver clusters. Scan statistics did scanning gradually across the space to identify the number of observed and expected observations inside the window at each location. The scanning window with the maximum likelihood was the most likely high performing clusters, and a $P$ value was assigned to this cluster.

4.1.6. Spatial Interpolation. The spatial interpolation technique is used to predict khat chewing for unsampled areas based on sampled EAs. For the prediction of unsampled EAs, we used the deterministic and geostatistical ordinary Kriging spatial interpolation technique using ArcGIS 10.7 software.

\subsection{Statistical Analysis}

4.2.1. Model Building. We fit four models: the null model without predictors, the model I with only individual-level variables, model II with only community-level variables, and model III both individual-level and community-level variables. These models were fitted using a STATA command melogit. For model comparison, we used the loglikelihood ratio (LLR) and deviance. The highest loglikelihood or the smallest deviance wins the best-fitted model. Therefore, model III which includes both individual and community-level variables was selected as the best fit model for the data.

4.2.2. Parameter Estimation Method. The fixed effects (a measure of association) were used to estimate the association between the likelihood of khat chewing and explanatory variables at both community and individual levels and were expressed as odds ratios with $95 \%$ confidence interval. Regarding the measures of variation (random-effects), the intracluster correlation coefficient (ICC), proportional change in community variance (PCV), and median odds ratio (MOR) were used.

The aim of the median odds ratio (MOR) is to translate the area level variance in the widely used odds ratio (OR) scale, which has a consistent and intuitive interpretation. The MOR is defined as the median value of the odds ratio between the area at the highest risk and the area at the lowest risk when randomly picking out two areas. The MOR can be conceptualized as the increased risk that (in median) would have if moving to another area with a higher risk.

It is computed by MOR $=\exp [\sqrt{ }(2 \times \mathrm{VA}) \times 0.6745][26]$, where VA is the area level variance and 0.6745 is the 75 th 
percentile of the cumulative distribution function of the normal distribution with mean 0 and variance 1 . See elsewhere for more detailed explanation [26]. The proportional change in variance is calculated as $\mathrm{PCV}=[(\mathrm{VA}-\mathrm{VB}) / \mathrm{VA}] * 100$ [27], where VA is the variance of the initial model and VB is the variance of the model with more terms.

\section{Results}

A total of 12,594 participants were comprised in the analysis. The prevalence of ever khat chewing in this study was $3418(27.14 \%)$ with $95 \%$ CI $26.37 \%$ to $27.92 \%$. Almost half of participants, 6426 (51.03\%), were in the age of 15-29 years. The majority of the participants $10,098(80.18 \%)$ were from rural, and most of them 5876 (46.66\%) were in the primary education class. The median age of the respondent was 29 with an interquartile range (IQR) of 21-39. Around two-thirds of 7705 (61.17\%), of participants, were married (Table 1).

\subsection{Spatial Analysis Result}

5.1.1. Spatial Distribution of Khat Chewing. As shown in Figure 2, a high proportion of chewing khat was observed in Dire Dawa, Harari, Southern Oromia, Somali, and Benishangul Gumuz regions which ranges from $61.9 \%$ to $100 \%$. The low proportion of khat chewing was observed in Amhara and some parts of Oromia and Tigray regions of Ethiopia.

5.1.2. Spatial Autocorrelation of Khat Chewing. In the EDHS 2016 survey, the spatial distribution of khat chewing in Ethiopia was nonrandom. The global Moran's I value was 0.49 ( $P$ value $<0.001)$ with a $Z$-score value of 30.63 with that there is a less than $1 \%$ likelihood that this clustered pattern could be the result of chance (Figure 3 ).

\subsubsection{Incremental Spatial Autocorrelation Khat Chewing.} To determine spatial clustering for khat chewing, global spatial statistics were estimated using Moran's I value. As shown in Figure 4 below, a statistically significant $Z$-score indicated at $357.42 \mathrm{~km}$ distances, where spatial processes promoting clustering are most pronounced. The incremental spatial autocorrelation indicated that a total of 10 distance bands were detected with a beginning distance of $357,428.11$ meters.

5.1.4. Hot Spot Analysis (Getis-OrdGi* Statistic). As shown in Figure 5 below, the red color indicated the more intense clustering of high (hot spot) proportion of khat chewing in the five years preceding the survey period and observed in Dire Dawa, Harari, Southern Oromia, Somali, and Benishangul Gumuz regions.

5.1.5. Spatial Scan Statistical Analysis. As shown in Figure 6 and Table 2 below, the red window indicated the identified significant clusters inside the window. In spatial scan statistics, a total of 140 most likely clusters were identified in EDHS 2016 survey. The most likely clusters of khat chewing were detected in most parts of Harari, Dire Dawa, southwestern part of Oromia, SNNPR, and Somali regions.
TABLE 1: Individual and community characteristics of adult men 1559 years in Ethiopia, EDHS 2016.

\begin{tabular}{|c|c|c|}
\hline Variable & Frequency $(n=12,594)$ & Percentage \\
\hline \multicolumn{3}{|l|}{ Ever chewed khat } \\
\hline Yes & 3418 & 27.14 \\
\hline No & 9176 & 72.86 \\
\hline \multicolumn{3}{|l|}{ Age group } \\
\hline $15-29$ & 6426 & 51.03 \\
\hline $30-44$ & 4173 & 33.13 \\
\hline $45-59$ & 1995 & 15.84 \\
\hline \multicolumn{3}{|l|}{ Sex of the household } \\
\hline Male & 11034 & 87.61 \\
\hline Female & 1560 & 12.59 \\
\hline \multicolumn{3}{|l|}{ Marital status } \\
\hline Married & 7705 & 61.17 \\
\hline Single & 489 & 38.83 \\
\hline \multicolumn{3}{|l|}{ Residence } \\
\hline Urban & 2496 & 19.82 \\
\hline Rural & 10098 & 80.18 \\
\hline \multicolumn{3}{|l|}{ Religion } \\
\hline Orthodox & 5677 & 45.07 \\
\hline Muslim & 3916 & 31.09 \\
\hline Protestant & 2745 & 21.80 \\
\hline Others* & 256 & 2.03 \\
\hline \multicolumn{3}{|l|}{ Education } \\
\hline No education & 3773 & 29.06 \\
\hline Primary & 5876 & 46.66 \\
\hline Secondary & 1846 & 14.66 \\
\hline Higher & 1099 & 8.73 \\
\hline \multicolumn{3}{|l|}{ Region } \\
\hline Tigray & 795 & 6.31 \\
\hline Afar & 82 & 0.65 \\
\hline Amhara & 3206 & 25.46 \\
\hline Oromia & 4713 & 37.43 \\
\hline Somali & 326 & 2.59 \\
\hline Benishangul Gumuz & 123 & 0.98 \\
\hline SNNPR & 2886 & 20.53 \\
\hline Gambela & 36 & 0.29 \\
\hline Harari & 31 & 0.25 \\
\hline Addis Ababa & 196209 & 4.93 \\
\hline Dire Dawa & 71 & 0.57 \\
\hline \multicolumn{3}{|l|}{ Media exposure } \\
\hline Yes & 8154 & 64.74 \\
\hline No & 4440 & 35.26 \\
\hline \multicolumn{3}{|l|}{ Wealth index } \\
\hline Poor & 4272 & 33.92 \\
\hline Middle & 2427 & 19.27 \\
\hline Rich & 5895 & 46.81 \\
\hline \multicolumn{3}{|l|}{ Working status } \\
\hline Yes & 11172 & 88.71 \\
\hline No & 1422 & 11.29 \\
\hline \multicolumn{3}{|l|}{ Alcohol drinking } \\
\hline Yes & 5873 & 46.64 \\
\hline No & 6721 & 53.36 \\
\hline
\end{tabular}

Note: others ${ }^{*}=$ Catholic, cultural belief. 


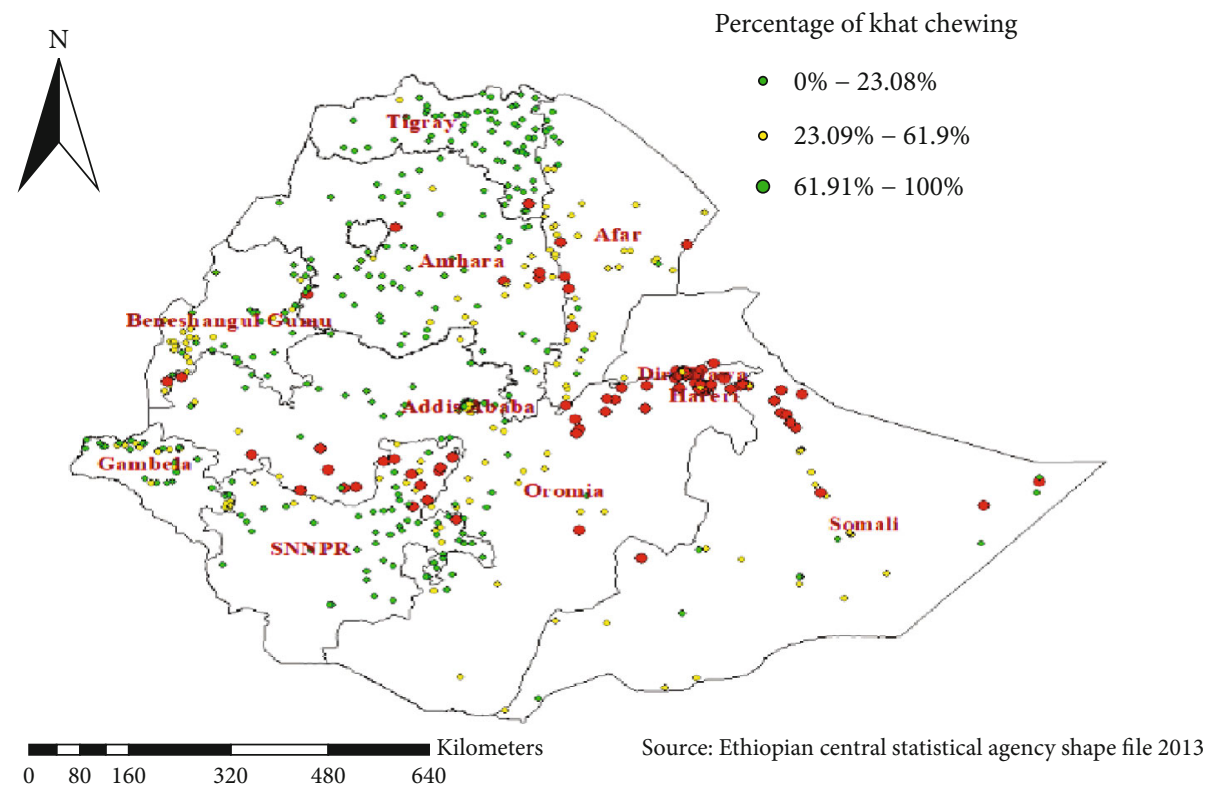

FIGURE 2: Spatial distribution of khat chewing among adults aging 15-59 across regions of the country, EDHS 2016.

\section{Spatial autocorrelation report}

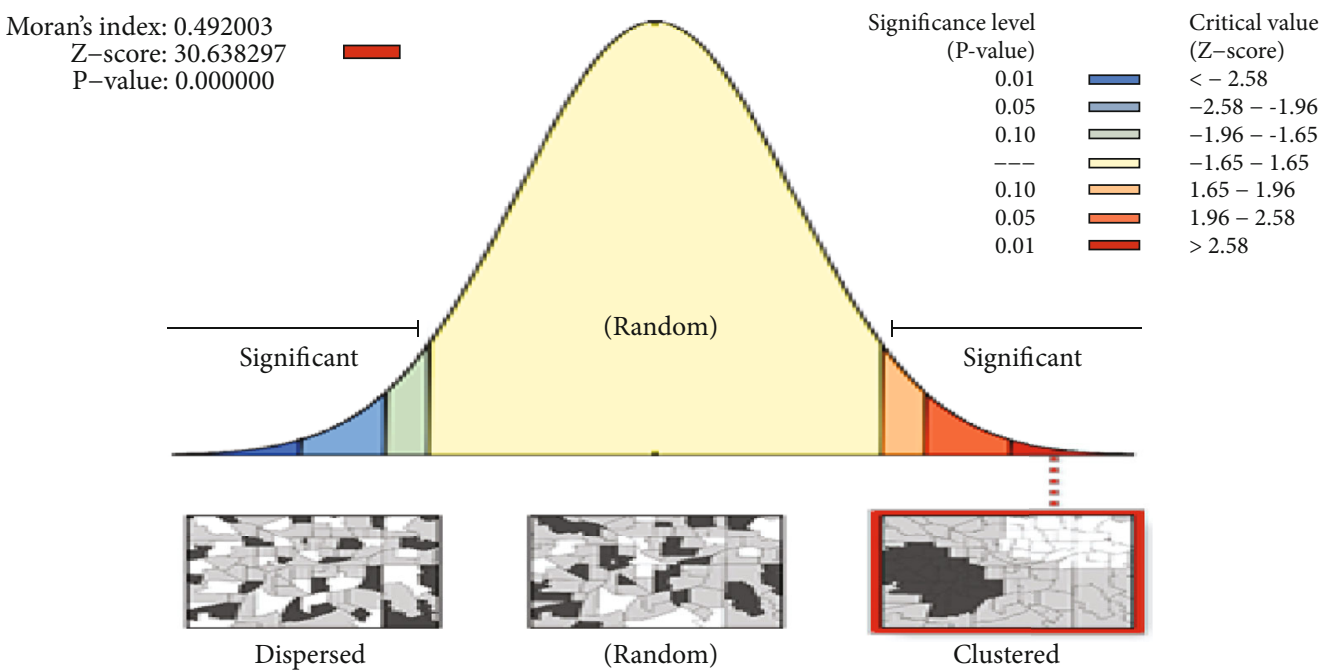

Given the Z-score of 30.6382974838 , there is a less than $1 \%$ likelihood that this clustered pattern could be the result of random chance.

FIGURE 3: Spatial autocorrelation of khat chewing among adults aging 15-59 across regions of the country, EDHS 2016.

Among the most likely clusters, 126 of them were primary clusters which are located at $9.303717 \mathrm{~N}, 41.792390 \mathrm{E}$ with a $200.29 \mathrm{~km}$ radius (log-likelihood ratio $($ LLR $)=480.60, P$ value $<0.001)$.

5.1.6. Spatial Interpolation. We used ordinary Kriging geostatistical interpolation for the prediction of khat chewing prevalence of unsampled areas. Based on geostatistical Kriging analysis, in 2016 EDHS, exclusively Dire Dawa, Harari, some parts of Oromia, Somali, and some parts of SNNPR had a prevalence of less $39.14 \%$ to $100 \%$ (Figure 7).

\subsection{Multilevel Logistic Regression Analysis}

5.2.1. The Random-Effects Analysis Result. The fixed effects (a measure of association) and the random intercepts for khat chewing are presented in Table 2 . The results of the empty model (model I) revealed that there was statistically significant variability in the odds of khat chewing with community variance $(\tau=4.73, P$ value $\leq 0.001)$. Similarly, the ICC in the empty model implied that $59.02 \%$ of the total variance in the khat chewing was attributed to differences between communities (residence and region). The community variance was 


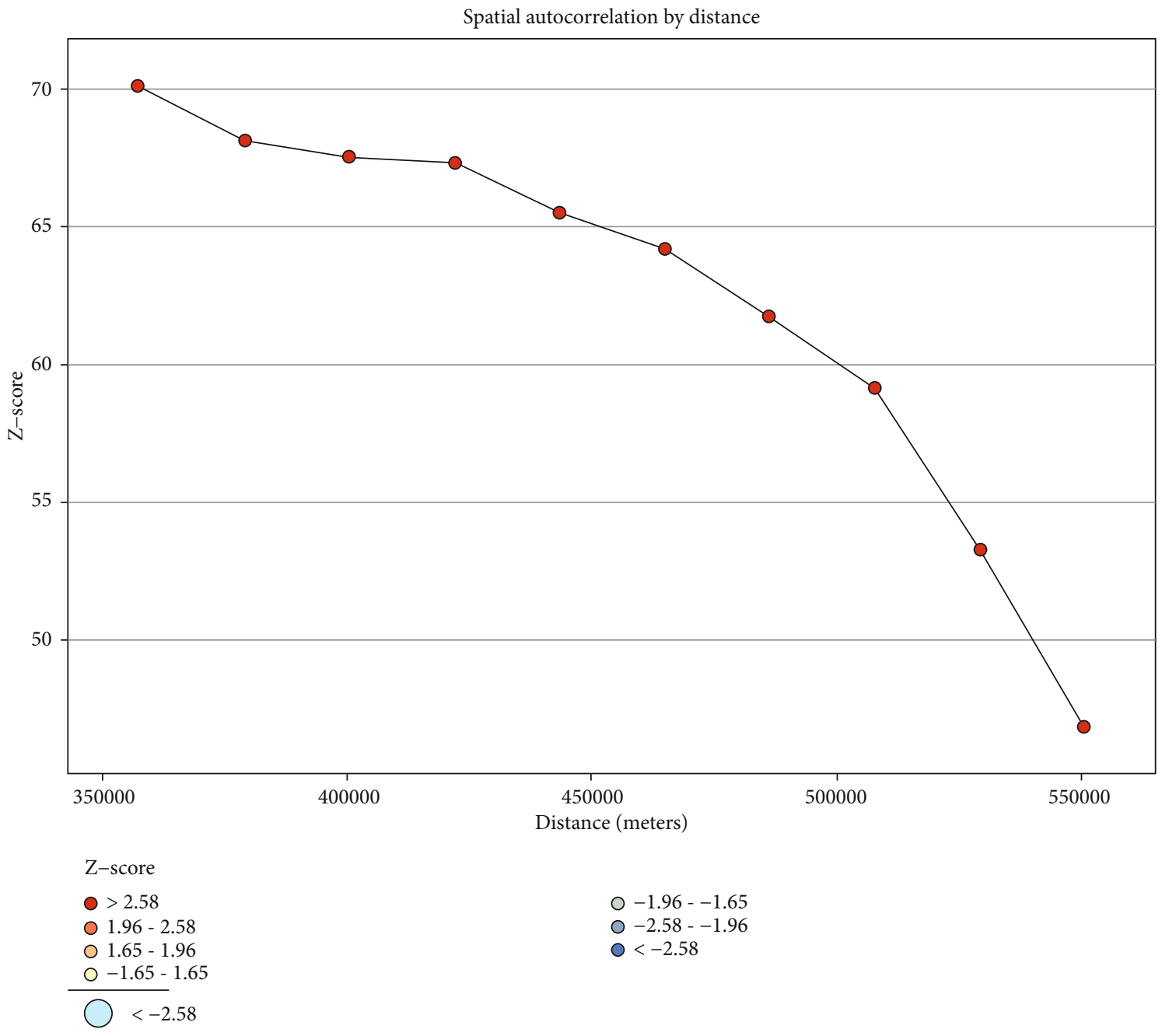

FIgURE 4: Spatial incremental autocorrelation of chewing khat in Ethiopia, EDHS 2016.

expressed as the intracluster correlation coefficient (ICC) and the median odds ratio (MOR). Moreover, the MOR was 4.6 (95\% CI 3.20, 6.58) which implied that the odds of having chewing khat was 4.6 times higher when men moved from low- to high-risk communities. This showed the existence of significant heterogeneity in khat chewing across different communities. In the full model (model adjusted for both individual- and community-level factors), community variance $($ community variance $=1.60 ;$ SE $0.15 ; P$ value $\leq 0.001)$ remained significant but reduced. About $36.84 \%$ of the total variance of chewing khat that can be attributed to the contextual-level factors remained significant even after considering some contextual risk factors. The proportional change in variance (PCV) in this model was $66.17 \%$ which showed that $66.17 \%$ of community variance observed in the null model was explained by both community- and individual-level variables (Table 3).

5.2.2. Fixed-Effects Analysis Result. In the bivariate analysis, age group, household headed, marital status, residence, religion, educational status, region, wealth index, media exposure, working status, and alcohol drinking were associated factors with khat chewing at a $P$ value of less than or equal to 0.2. Consequently, these variables were subjected to multivariable analysis, and it was noted that age group, marital status, religion, region, media exposure, working status, and alcohol drinking were statistically significant variables associated with khat chewing at a $P$ value of 0.05 .

The odds of chewing khat among Ethiopian male adults age group 30-44 and 45-59 increase by $60 \%$ and $33 \%$ as compared to age group $15-29$ years $(\mathrm{AOR}=1.60,95 \% \mathrm{CI}: 1.37$, 1.86; $\mathrm{AOR}=1.33,95 \% \mathrm{CI}: 1.09,1.61$, respectively). Being single increases the odds of chewing khat by $86 \%$ as compared to married adults ( $\mathrm{AOR}=1.86,95 \% \mathrm{CI}$ : 1.64, 2.12). The odds of chewing khat among Muslim religion followers were 15.06 times higher as compared to Orthodox religion followers $(\mathrm{AOR}=15.09,95 \% \mathrm{CI}: 11.94,18.97)$. The odds of chewing khat increase by 2.48 times higher among men who had work as compared to their counterparts $(\mathrm{AOR}=2.48,95 \% \mathrm{CI}$ : $2.08,2.95)$. The odds of chewing chat decrease by $33 \%$ among media exposed male adults as compared to nonexposed $(\mathrm{AOR}=0.77,95 \% \mathrm{CI}: 0.68,0.86)$. The likelihood of chewing chat among alcohol drinkers was 3.75 times higher as compared to nondrinkers (AOR $=3.75,95 \% \mathrm{CI}: 3.110,4.53)$. The odds of khat chewing vary in region (Table 3 ). 

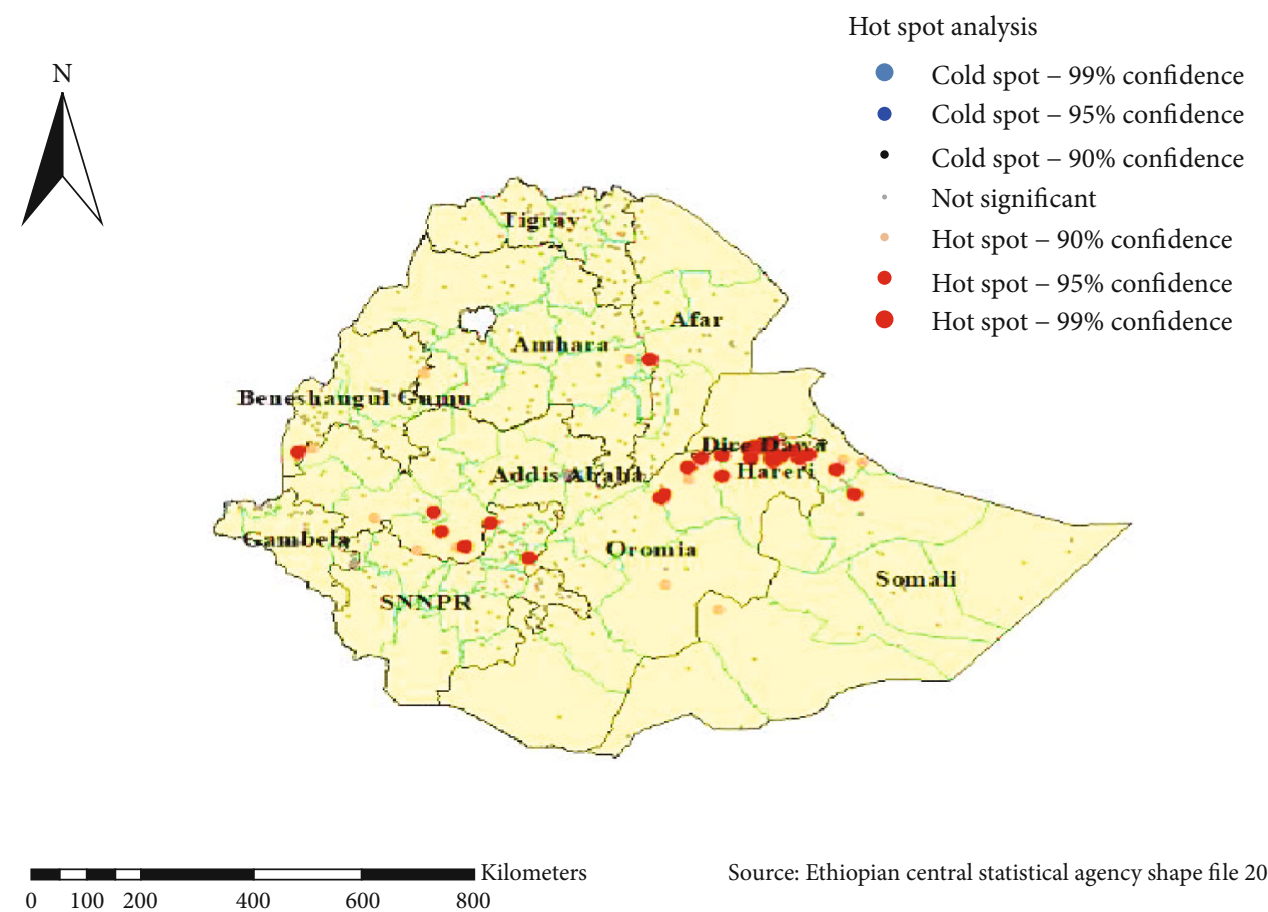

Source: Ethiopian central statistical agency shape file 2013

FIGURE 5: Hot spot analysis of khat chewing in Ethiopia, EDHS 2016.
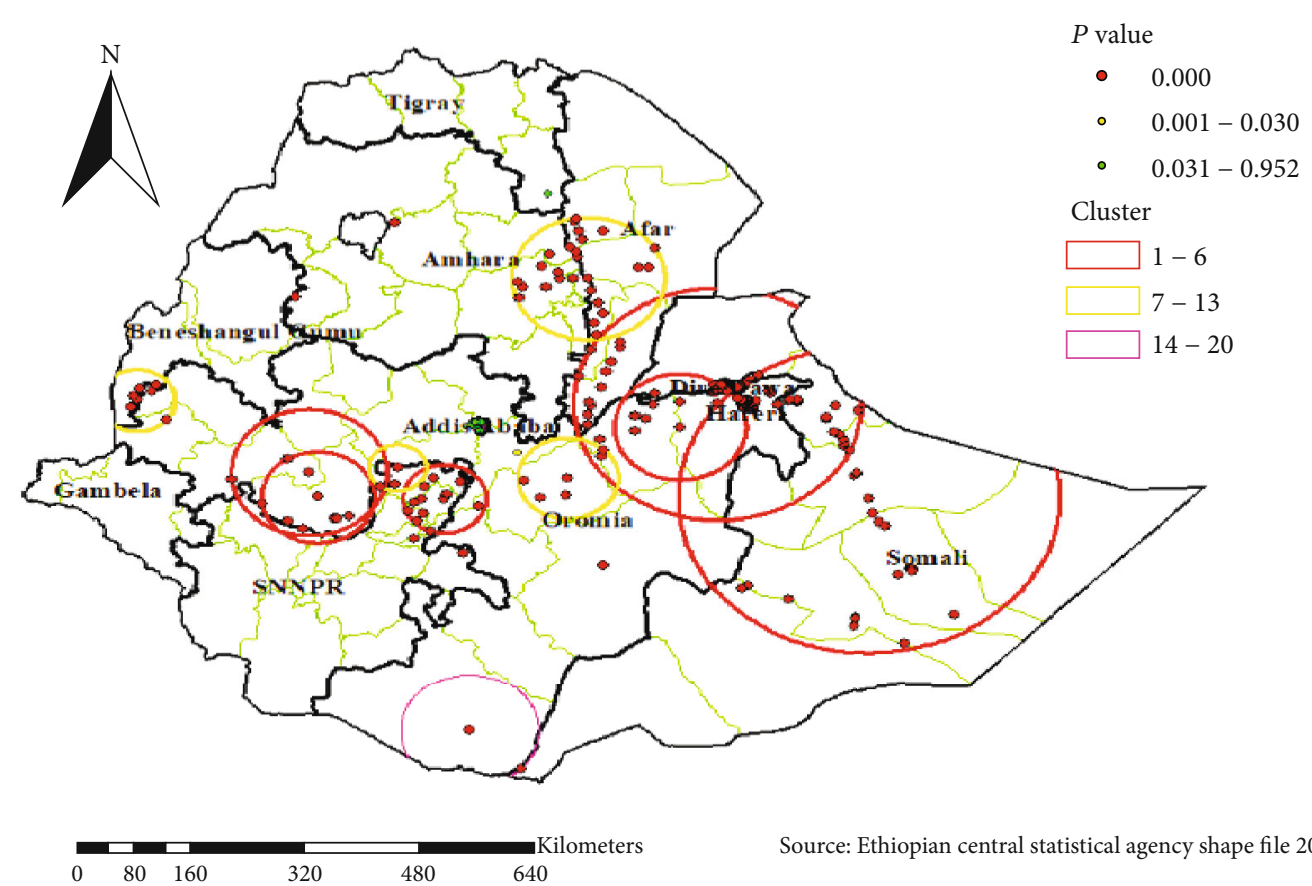

Source: Ethiopian central statistical agency shape file 2013

FIgURE 6: Spatial scan statistics of khat chewing in Ethiopia, EDHS 2016.

\section{Discussion}

This study showed the spatial distribution and factors associated with khat chewing among male adults in Ethiopia by using the Ethiopian Demographic and Health Survey 2016. The study revealed that khat chewing was more common in Dire Dawa, Harari, Southern Oromia, Somali, and Benishan- gul Gumuz regional states of Ethiopia. Age group, marital status, religion, working status, media exposure, and alcohol drinking were identified as associated factors with khat chewing in Ethiopia.

This study revealed that the spatial distribution of khat chewing in Ethiopia was nonrandom. Khat chewing was highly clustered in Dire Dawa, Harari, Southern Oromia, 
TABLE 2: SaTScan analysis of khat chewing among men in the last five years in Ethiopia, EDHS 2016.

\begin{tabular}{|c|c|c|c|c|c|c|c|}
\hline Cluster type & $\begin{array}{l}\text { Significant enumeration areas } \\
\text { (clusters) detected }\end{array}$ & Coordinates/radius & Populations & Cases & $\mathrm{RR}$ & LLR & $P$ value \\
\hline Primary & $\begin{array}{c}453,557,441,594,166,30,473,380,74, \\
311,613,273,151,631,535,519,282,471, \\
202,111,607,43,5,644,173,25,443, \\
185,352,606,444,467,115,390,546,614, \\
190,363,27,393,383,385,514,610,179, \\
224,28,493,60,228,101,133,29,56,397, \\
140,500,238,157,257,418,58,329,580, \\
240,396,513,387,534,44,523,587,242, \\
495,483,194,321,281,381,288,357,68, \\
419,454,501,212,436,642,93,622,372,1, \\
307,566,186,491,333,8,210,412,64,57, \\
439,506,476,277,568,527,564,39,336, \\
135,22,37,122,51,245,116,230,49,71, \\
239,529,251,573,33,484,102,214\end{array}$ & $\begin{array}{c}(9.303717 \mathrm{~N}, 41.792390 \mathrm{E}) / \\
200.29 \mathrm{~km}\end{array}$ & 1110 & 955 & 4.02 & 946.56 & $\leq 0.001$ \\
\hline Secondary & $\begin{array}{c}372,93,412,333,476,506,453,491 \\
441,557,594,30,25,166\end{array}$ & $\begin{array}{c}(8.949349 \mathrm{~N}, 41.312400 \mathrm{E}) / \\
91.51 \mathrm{~km}\end{array}$ & 496 & 453 & 3.73 & 480.60 & $\leq 0.001$ \\
\hline
\end{tabular}
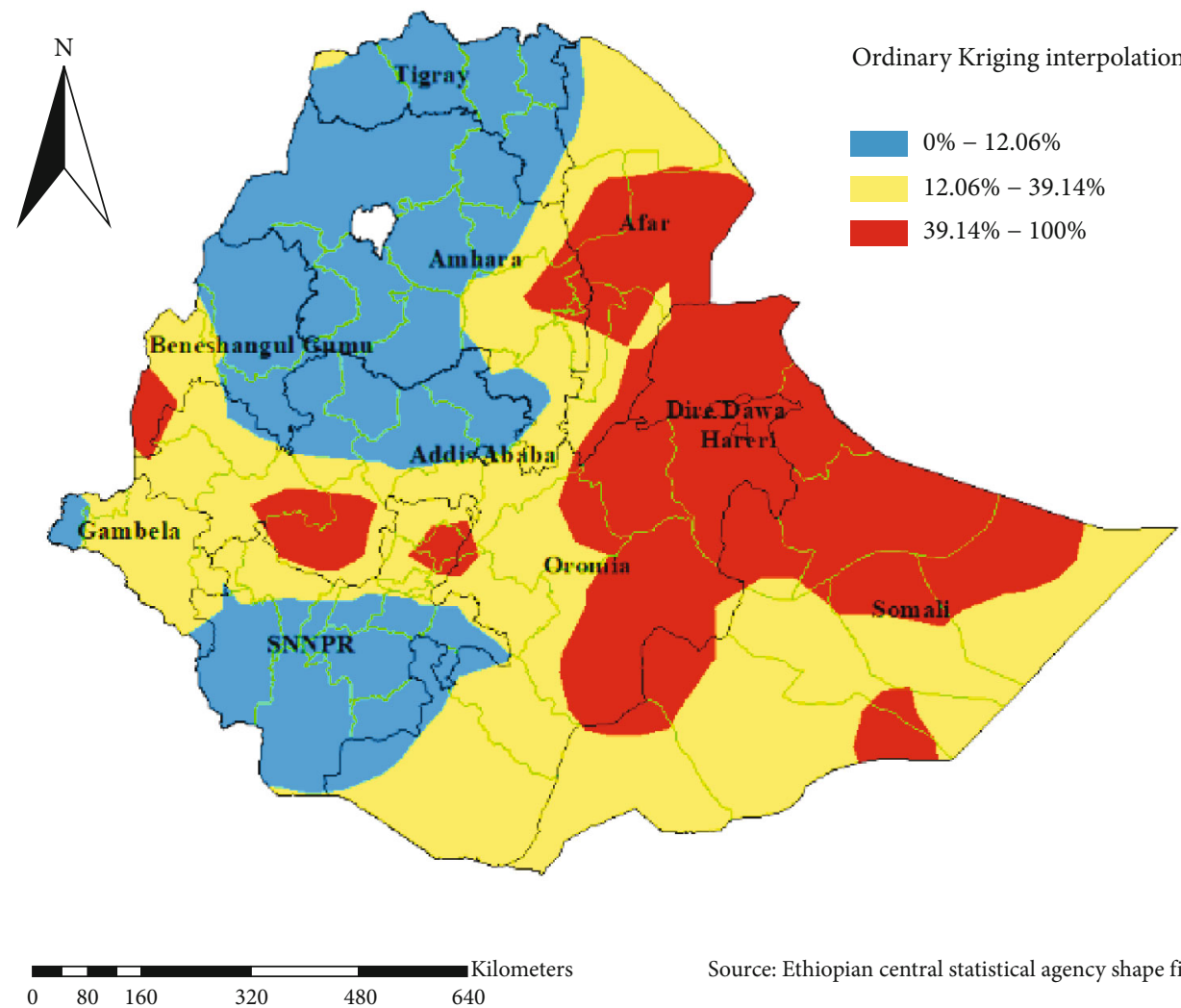

Source: Ethiopian central statistical agency shape file 2013

FIGURE 7: Spatial interpolation of khat chewing among males in Ethiopia, EDHS 2016.

Somali, and Benishangul Gumuz regional state of Ethiopia. In line with this, high proportion clustering, spatial scan statistic analysis revealed that 126 significant clusters were found.

In this finding, different factors of khat chewing were assessed by the logistic regression model. Individuals who are residents of Afar, Amhara, Oromia, Somali, Benishangul Gumuz, SNNPR, Gambela, Harari, Addis Ababa, and Dire
Dawa had higher odds of khat use when compared with Tigray. This study is in line with spatial analysis of the result of Figure 4; the reason might be due to the fact that nowadays khat is transported throughout Ethiopia due to the expansions of both land and air transportation. The powerful force has perhaps increased market prospects and prices of khat [20]. 
TABLE 3: Multivariable multilevel logistic regression analysis of both individual- and community-level factors associated with khat chewing in Ethiopia, EDHS 2016.

\begin{tabular}{|c|c|c|c|c|}
\hline \multirow{2}{*}{$\begin{array}{l}\text { Individual- and community- } \\
\text { level variables }\end{array}$} & \multicolumn{4}{|c|}{ Models } \\
\hline & $\begin{array}{c}\text { Null model } \\
\text { AOR }(95 \% \text { CI })\end{array}$ & $\begin{array}{c}\text { Model I } \\
\text { AOR }(95 \% \text { CI })\end{array}$ & $\begin{array}{c}\text { Model II } \\
\text { AOR }(95 \% \text { CI }) \\
\end{array}$ & $\begin{array}{c}\text { Model III } \\
\text { AOR }(95 \% \text { CI })\end{array}$ \\
\hline \multicolumn{5}{|l|}{ Men age } \\
\hline $15-20$ years & & 1 & & 1 \\
\hline 20-34 years & & $1.67(1.43,1.94)$ & & $1.60(1.37,1.86)^{*}$ \\
\hline $35-49$ years & & $1.38(1.13,1.67)$ & & $1.33(1.09,1.61)^{*}$ \\
\hline \multicolumn{5}{|l|}{ Household head } \\
\hline Male & & 1 & & 1 \\
\hline Female & & $1.03(0.88,1.20)$ & & $0.99(0.85,1.16)$ \\
\hline \multicolumn{5}{|l|}{ Marital status } \\
\hline Had a partner & & 1 & & 1 \\
\hline Not having a partner & & $2.08(1.55,2.33)$ & & $1.86(1.64,2.12)^{*}$ \\
\hline \multicolumn{5}{|l|}{ Religion } \\
\hline Orthodox & & 1 & & 1 \\
\hline Muslim & & $16.1(12.74,20.35)$ & & $15.06(11.9,18.9)^{*}$ \\
\hline Protestant & & $0.48(0.36,0.64)$ & & $0.43(0.34,1.05)$ \\
\hline Others & & $0.89(0.52,1.52)$ & & $0.77(0.46,1.29)$ \\
\hline \multicolumn{5}{|l|}{ Men education } \\
\hline Unable to read and write & & 1 & & 1 \\
\hline Primary education & & $1.16(0.99,1.37)$ & & $1.10(0.93,1.29)$ \\
\hline Secondary education & & $1.26(1.02,1.55)$ & & $1.09(0.89,1.35)$ \\
\hline Higher education & & $1.37(1.10,1.74)$ & & $1.17(0.94,1.47)$ \\
\hline \multicolumn{5}{|l|}{ Men occupation } \\
\hline Not working & & 1 & & 1 \\
\hline Working & & $2.24(2.08,2.94)$ & & $2.48(2.08,2.95)^{*}$ \\
\hline \multicolumn{5}{|l|}{ Media exposure } \\
\hline No exposed & & 1 & & 1 \\
\hline Exposed & & $0.86(0.68,0.95)$ & & $0.77(0.65,0.87)^{*}$ \\
\hline \multicolumn{5}{|l|}{ Wealth index } \\
\hline Poor & & 1 & & 1 \\
\hline Middle & & $0.99(0.80,1.22)$ & & $0.98(0.79,1.22)$ \\
\hline Richer & & $1.24(1.02,1.50)$ & & $1.00(0.82,1.23)^{*}$ \\
\hline \multicolumn{5}{|l|}{ Alcohol drinking } \\
\hline No & & 1 & & \\
\hline Yes & & $3.45(2.84,4.18)$ & & $3.75(3.10,4.53)^{*}$ \\
\hline \multicolumn{5}{|l|}{ Residence } \\
\hline Urban & & & 1 & 1 \\
\hline Rural & & & $1.06(0.74,1.53)$ & $0.78(0.55,1.10)$ \\
\hline \multicolumn{5}{|l|}{ Region } \\
\hline Tigray & & & & 1 \\
\hline Afar & & & $24.87(12.13,50.99)$ & $8.36(4.52,16.49)^{*}$ \\
\hline Amhara & & & $2.85(1.42,5.70)$ & $2.04(1.11,3.74)^{*}$ \\
\hline Oromia & & & $30.11(15.45,58.66)$ & $20.10(11.09,36.44)^{* * *}$ \\
\hline Somali & & & $38.30(19.40,75.62)$ & $12.34(6.63,22.95)^{*}$ \\
\hline Benishangul Gumuz & & & $8.58(4.15,17.75)$ & $4.03(2.12,7.67)^{*}$ \\
\hline SNNPR & & & $5.12(2.59,10.15)$ & $11.48(6.1,21.2)^{*}$ \\
\hline
\end{tabular}


TABLE 3: Continued.

\begin{tabular}{|c|c|c|c|c|}
\hline \multirow[b]{2}{*}{$\begin{array}{l}\text { Individual- and community- } \\
\text { level variables }\end{array}$} & \multicolumn{4}{|c|}{ Models } \\
\hline & $\begin{array}{c}\text { Null model } \\
\text { AOR }(95 \% \mathrm{CI})\end{array}$ & $\begin{array}{c}\text { Model I } \\
\text { AOR }(95 \% \mathrm{CI})\end{array}$ & $\begin{array}{c}\text { Model II } \\
\text { AOR }(95 \% \text { CI })\end{array}$ & $\begin{array}{c}\text { Model III } \\
\text { AOR }(95 \% \text { CI })\end{array}$ \\
\hline Gambela & & & $10.59(5.13,21.88)$ & $19.48(10.1,37.2)^{*}$ \\
\hline Harari & & & $208(97.5,445)$ & $122(61,241)^{*}$ \\
\hline Addis Ababa & & & $23.31(11.15,48.71)$ & $15.48(8.37,29.97)^{*}$ \\
\hline Dire Dawa & & & $110(5.93,233.17)$ & $58.31(30.0,113.1)^{*}$ \\
\hline \multicolumn{5}{|l|}{ Random effects } \\
\hline ICC $\%$ & 59.02 & 49.20 & 43.36 & 32.84 \\
\hline PCV\% & 1 & 32.76 & 46.93 & 66.17 \\
\hline MOR & 7.96 & 5.47 & 10.96 & 4.60 \\
\hline \multicolumn{5}{|l|}{ Model fitness } \\
\hline Log-likelihood ratio & -5729 & -4955 & -5567 & -4783 \\
\hline Deviance & 11458 & 9910 & 11134 & 9566 \\
\hline
\end{tabular}

NB: $*=$ significant at $P$ value $=0.05 ; \mathrm{CI}=$ confidence interval; $\mathrm{AOR}=$ adjusted odds ratio; others = traditional religion followers.

When compared with people less than 15-29 years of age, all older (30-44 and 45-59) people have a higher risk of being a khat chewer. This finding is in line with other studies $[23,24]$. The possible reason could be young people tend to be under family control which reduces their risk of being a chat chewer.

In this study, Muslim religion followers were at a higher risk of being khat chewer when compared to Orthodox Christians. This finding is supported by the research done in Chiro town [20], Dera woreda [21], and Butajira [17]. This could be due to the fact that khat use was acceptable in the sociocultural and functional purposes with a restriction of the frequency, amount, and type of khat [18]. Another reason might be to get the maximum concentration level during praying, to increase socialization, for confirming norms, and for stabilizing emotions [17].

In this study, those men who are single increased odds of khat chewing 2.48 times than married. This might be due to the reason that individuals who are single are high risk for substance use and unmarried individuals are positively associated with khat chewing [28].

The odds of khat chewing were increased by 2.48 times higher among individuals who have work when compared with counterparts. Perhaps, the working individuals may enable to use khat than individuals who had no work who spent their time with khat chewing.

In our study, the odds of khat chewing were decreased by $33 \%$ among those who attend mass media as compared to those who did not attend. This could be due to the fact that individuals who read magazines and newspapers, listen to the radio, and watch television had the awareness of the bad result of khat use, like depression, anxiety, sleep disorder, conflict in the family, reduced appetite, and neurological and dental problems, making them less likely to chew khat [29-32].

The odds of khat chewing are increased by 3.75 times higher among alcohol drinkers when compared with a nondrinker. This is consistent with another finding; harmful drinking is common among khat users that account for $53.9 \%$ [33]. The possible reason might be that alcohol drink- ing is used to break the stimulating effect of khat; therefore, alcohol is helpful for sleep and used as self-treatment from khat-induced distress [18].

We have also found a significant difference in the risk of khat chewing among the regions of Ethiopia with the Tigray region the least likely region to chew khat. This finding is in line with another study conducted in Gondar, Ethiopia [34]. This could be due to the cultural difference and political instability in the high-risk areas of khat chewing like Ethiopian Somali which leads to stress.

This study has strengths of nationally representative data, and advanced statistical models were used to account correlations within clusters. However, this study has limitations of the cross-sectional nature of the study, which may not indicate true causality. Besides, the effects of the health system and health worker factors were not assessed during data collection.

\section{Conclusions}

In Ethiopia, the spatial distribution of khat chewing among adult men was nonrandom. A high proportion of khat chewing was observed in Dire Dawa, Harari, Southern Oromia, Somali, and Benishangul Gumuz regions. Older age group, being single, alcohol drinker, media unexposed, had no work, and Muslim religion followers were factors affecting khat chewing. Policymakers should be given spatial attention in reducing the prevalence of chewing khat by teaching the health impact of khat chewing through media in the identified regions.

\section{Abbreviations}

AOR: Adjusted odds ratio

CI: Confidence interval

COR: Crude odds ratio

LLR: Likelihood ratio

RR: $\quad$ Relative risk

SNNPR: Southern Nations, Nationalities, and People's Region. 


\section{Data Availability}

The data used to support the findings of this study are available from the corresponding author upon request.

\section{Ethical Approval}

The data is secondary, and we received a permission letter from measure DHS at http://www.measuredhs.com.

\section{Consent}

According to the EDHS 2016 report, written informed consent from study participants age less than 16 was obtained from the guardian. The detail of the report can be accessed at (3).

\section{Conflicts of Interest}

The authors declared that they have no competing interests.

\section{Authors' Contributions}

ZTT and TAZ conceived the study, are involved in the study design and data analysis, drafted the manuscript, and critically reviewed the manuscript. Both authors read and approved the final manuscript.

\section{Acknowledgments}

We would like to thank the Ethiopian Central Statistics Agency for providing us with all the relevant secondary data used in this study. Finally, we would like to thank all who directly or indirectly supported us.

\section{References}

[1] K. A. Sheikh, M. El-Setouhy, U. Yagoub, R. Alsanosy, and Z. Ahmed, "Khat chewing and health related quality of life: crosssectional study in Jazan region, Kingdom of Saudi Arabia," Health and Quality of Life Outcomes, vol. 12, no. 1, article 1477-7525-12-44, p. 44, 2014.

[2] N. T. Wabe, "Chemistry, pharmacology, and toxicology of khat (catha edulis forsk): a review," Addiction and Health, vol. 3, no. 3-4, pp. 137-149, 2011.

[3] World Bank, Yemen toward qat demand reduction, 2012, Report no. 39738-YE, June 2007; United Nations Office on Drugs and Crime (UNODC), World Drug Report, New York.

[4] J. Stefan and B. Mathew, "Khat Chewing: An Emerging Drug Concern in Australia?," Australian \& New Zealand Journal of Psychiatry, vol. 39, no. 9, pp. 842-843, 2005.

[5] J. Hoare and D. Moon, Drug misuse declared: findings from the 2009/10 British Crime Survey. Home Office Statistical Bulletin 13/10, Home Office, London, 2010.

[6] C. Ward and P. Gatter, Qat in Yemen: towards a policy and an action plan, World Bank, Sana'a, Yemen, 2000.

[7] P. Griffiths, M. Gossop, S. Wickenden, J. Dunworth, K. Harris, and C. Lloyd, "A transcultural pattern of drug use: qat (khat) in the UK," The British Journal of Psychiatry, vol. 170, no. 3, article S0007125000146641, pp. 281-284, 1997.
[8] M. S. Mahfouz, B.-e. E. A. Rahim, Y. M. H. Solan, A. M. Makeen, and R. M. Alsanosy, "Khat Chewing Habits in the Population of the Jazan Region, Saudi Arabia: Prevalence and Associated Factors," PLoS One, vol. 10, no. 8, p. e0134545, 2015.

[9] Ethiopian Demographic and Health Survey, vol. 2017, Cent Stat Agency Addis Ababa, Ethiop DHS Progr ICF, Rockville, Maryland, USA, 2016.

[10] ACMD, "Khat (qat): assessment of risk to the individual and communities in the UK," 2005.

[11] W. Sykes, N. Coleman, P. Desai, C. Groom, M. Gure, and R. Howarth, "Perceptions of the Social Harms Associated with Khat Use: Summary," PsycEXTRA Datase, 2010.

[12] W. Fowzi and A. Klein, Patterns of khat use among Camden Somali community Drugscope, 2004.

[13] Y. Mulugeta, "Khat chewing and its associated factor among college students in Bahir Dar town, Ethiopia," Science Journal of Public Health, vol. 1, no. 5, article 2510142, p. 209, 2013.

[14] R. M. Alsanosy, M. S. Mahfouz, and A. M. Gaffar, "Khat chewing among students of higher education in Jazan region, Saudi Arabia: prevalence, pattern, and related factors," BioMed Research International, vol. 2013, Article ID 487232, 7 pages, 2013.

[15] D. Wazema and K. Madhavi, "Prevalence of Khat abuse and associated factors among undergraduate students of Jimma University, Ethiopia," International Journal of Research in Medical Sciences, pp. 1751-1757, 2015.

[16] A. Lakew, B. Tariku, N. Deyessa, and Y. Reta, "Prevalence of \&lt;i\&gt;Catha edulis\&lt;/i\&gt; (khat) chewing and its associated factors among ataye secondary school students in northern Shoa, Ethiopia," Advances in Applied Sociology, vol. 4, no. 10, pp. 225-233, 2014.

[17] A. Alem, D. Kebede, and G. Kullgren, "The prevalence and socio-demographic correlates of khat chewing in Butajira, Ethiopia," Acta Psychiatr Scand., vol. 100, pp. 84-91, 1999.

[18] A. Mihretu, S. Teferra, and A. Fekadu, "Problematic khat use as a possible risk factor for harmful use of other psychoactive substances: a mixed method study in Ethiopia," Substance Abuse Treatment, Prevention, and Policy, vol. 12, no. 1, article 132, p. 47, 2017.

[19] B. A. Dachew, B. B. Bifftu, and B. T. Tiruneh, "Khat use and its determinants among university students in northwest Ethiopia: a multivariable analysis," International Journal of Medical Science and Public Health, vol. 4, no. 3, p. 319, 2015.

[20] D. Haile and Y. Lakew, "Khat chewing practice and associated factors among adults in Ethiopia: further analysis using the 2011 demographic and health survey," PLoS One, vol. 10, no. 6, article e0130460, 2015.

[21] A. Zeleke, W. Awoke, E. Gebeyehu, and F. Ambaw, "Khat chewing practice and its perceived health effects among communities of Dera Woreda, Amhara region, Ethiopia," Open Journal of Epidemiology, vol. 3, no. 4, pp. 160-168, 2013.

[22] A. Gebrie, A. Alebel, A. Zegeye, and B. Tesfaye, "Prevalence and predictors of khat chewing among Ethiopian university students: a systematic review and meta-analysis," PLoS One, vol. 13, no. 4, article e0195718, 2018.

[23] A. A. Reda, A. Moges, S. Biadgilign, and B. Y. Wondmagegn, "Prevalence and determinants of khat (Catha edulis) chewing among high school students in eastern Ethiopia: a cross-sectional study," PLoS One, vol. 7, no. 3, article e33946, 2012. 
[24] E. Dires and M. Soboka, "Factors associated with khat chewing among high school students in Jimma town southwest Ethiopia," Journal of Psychiatry, vol. 19, no. 4, 2016.

[25] T. Waldhör, "The spatial autocorrelation coefficient MORAN'SI UNDER HETEROSCEDASTICITY," Stat Med, vol. 15, no. 7-9, pp. 887-892, 1996.

[26] H. Goldstein, W. Browne, and J. Rasbash, "Partitioning variation in multilevel models," Understanding Statistics, vol. 1, no. 4, pp. 223-231, 2002.

[27] J. Merlo, M. Yang, B. Chaix, J. Lynch, and L. Råstam, “A brief conceptual tutorial on multilevel analysis in social epidemiology: investigating contextual phenomena in different groups of people," Journal of Epidemiology \& Community Health, vol. 59, no. 9, pp. 729-736, 2005.

[28] A. T. Wondemagegn, M. C. Cheme, and K. T. Kibret, "Perceived psychological, economic, and social impact of khat chewing among adolescents and adults in Nekemte Town, East Welega Zone, West Ethiopia," Biomed Res Int., vol. 2017, article 7427892, pp. 1-9, 2017.

[29] M. B. Etana, "Economic and social impacts of khat (Catha edulis Forsk) chewing among youth in Sebeta town, Oromia Ethiopia," Biomedical Statistics and Informatics, vol. 3, no. 2, article 2750072 , p. 29, 2018

[30] A. Yahya, Y. Rajeshwar, T. Eticha, G. Kahsay, D. Ali, and H. Gebretsadik, Socio-economic and health effects of khat chewing in Mekelle, Tigray region, Ethiopia, 2016.

[31] A. M. Elhadrani and M. A. AlHoot, "An association between khat and diabetes," Egyptian Journal of Surgery, 2000.

[32] H. M. A. Ageely, "Health and socio-economic hazards associated with khat consumption," J Family Community Med., vol. 15, no. 1, pp. 3-11, 2008.

[33] A. Esmael, "Psychoactive substances use (khat, alcohol and tobacco) and associated factors among Debre Markos University students, north-west Ethiopia, 2013," Journal of Defense Management, vol. 4, no. 1, 2014.

[34] A. E. Sinshaw, "Prevalence and associated factors of khat chewing among Atse Fasil campus Students, University of Gondar, north west Ethiopia June 2013," Journal of Psychology \& Clinical Psychiatry, vol. 1, no. 6, 2014. 